RFP-1813

August 15, 1972
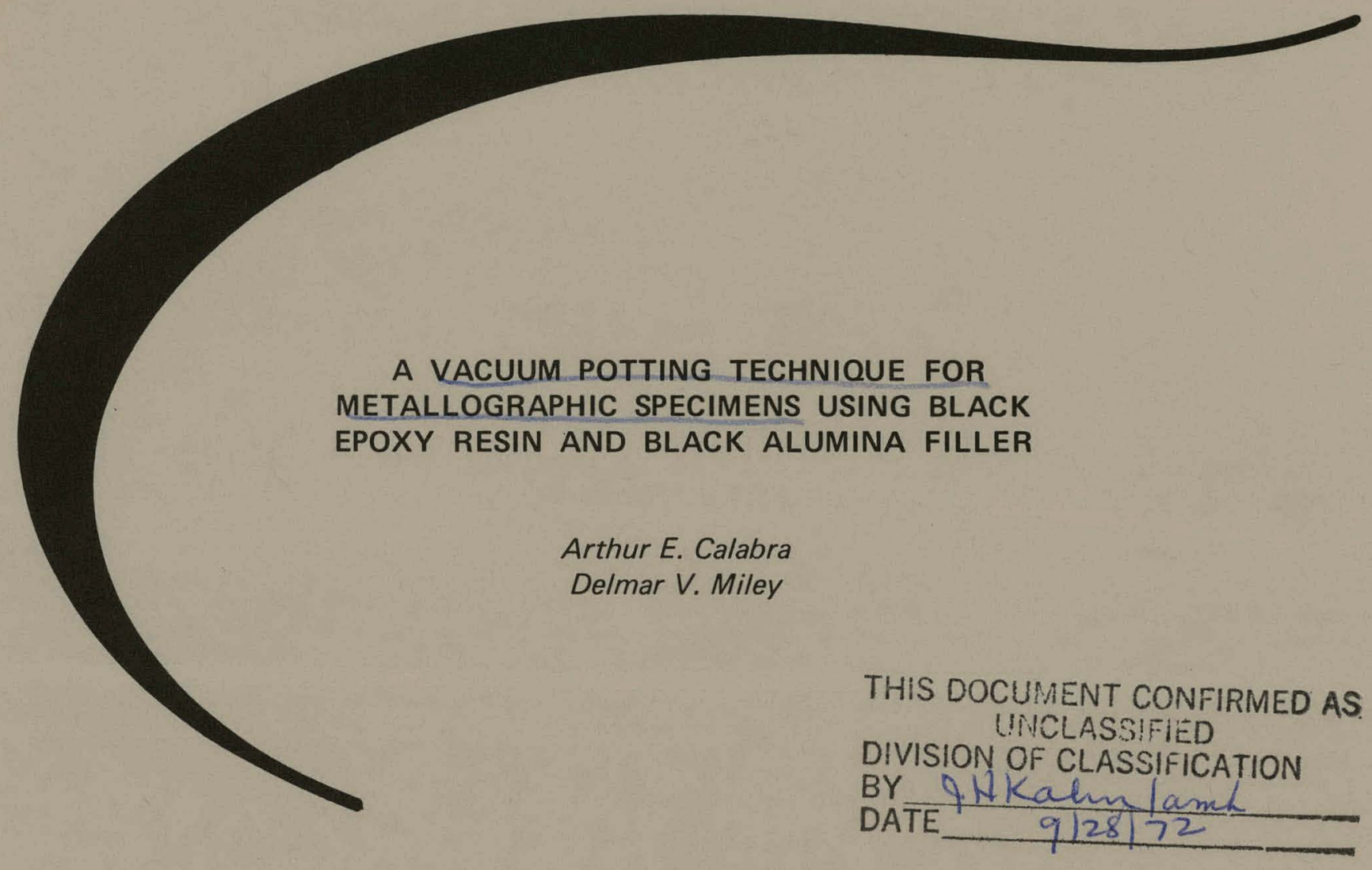

A VACUUM POTTING TECHNIQUE FOR METALLOGRAPHIC SPECIMENS USING BLACK EPOXY RESIN AND BLACK ALUMINA FILLER

Arthur E. Calabra

Delmar V. Miley

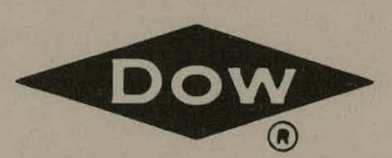

DOW CHEMICAL U.S.A. ROCKY FLATS DIVISION

P. O. BOX 888

GOLDEN, COLORADO 80401

U. S. ATOMIC ENERGY COMMISSION CONTRACT AT(29-1)-1106 


\section{DISCLAIMER}

This report was prepared as an account of work sponsored by an agency of the United States Government. Neither the United States Government nor any agency Thereof, nor any of their employees, makes any warranty, express or implied, or assumes any legal liability or responsibility for the accuracy, completeness, or usefulness of any information, apparatus, product, or process disclosed, or represents that its use would not infringe privately owned rights. Reference herein to any specific commercial product, process, or service by trade name, trademark, manufacturer, or otherwise does not necessarily constitute or imply its endorsement, recommendation, or favoring by the United States Government or any agency thereof. The views and opinions of authors expressed herein do not necessarily state or reflect those of the United States Government or any agency thereof. 


\section{DISCLAIMER}

Portions of this document may be illegible in electronic image products. Images are produced from the best available original document. 


\section{LEGAL NOTICE}

This report was prepared as an account of work sponsored by the United States Government. Neither the United States nor the United Stales Alumic Energy Commission, nor any of their employees, nor any of their contractors, subcontractors, or their employees, makes any warranty, expressed or implied, or assumes any legal liability or responsibility for the accuracy, completeness or usefulness of any information, apparatus, product or process disclosed, or represents that its use would not infringe privately owned rights.

Printed in the United States of America

Available from the

National Technical Information Service

U. S. Department of Commerce

Springfield, Virginia 22151

Price: Printed Copy $\$ 3.00$; Microfiche $\$ 0.95$ 


\title{
A VACUUM POTTING TECHNIQUE FOR METALLOGRAPHIC SPECIMENS USING BLACK EPOXY RESIN AND BLACK ALUMINA FILLER
}

\author{
Arthur E. Calabra \\ Delmar V. Miley
}

This report was prepared as an account of work sponsored by the United States.Govcrnment. Neither the United States nor the United States Atomic Energy Commission, nor any of their employees, nor any of their contractors, subcontractors, or their employees, unakis ony warranty, a vpress or implied. or assumes any legal liability or responsibility for the accuracy, completeness or usefulness of any information, apparatus, product or process disclosed, or represents that its use would not infringe privately owned rights.

DOW CHEMICAL U.S.A.

ROCKY FLATS DIVISION

P. U. B̈UX 888

GOLDEN, COLORADO 80401

Prepared under Contract AT(29-1)-1106

for the

Albuquerque Operations Office

U. S. Atomic Energy Commission 
RFP-1813 


\section{CONTENTS}

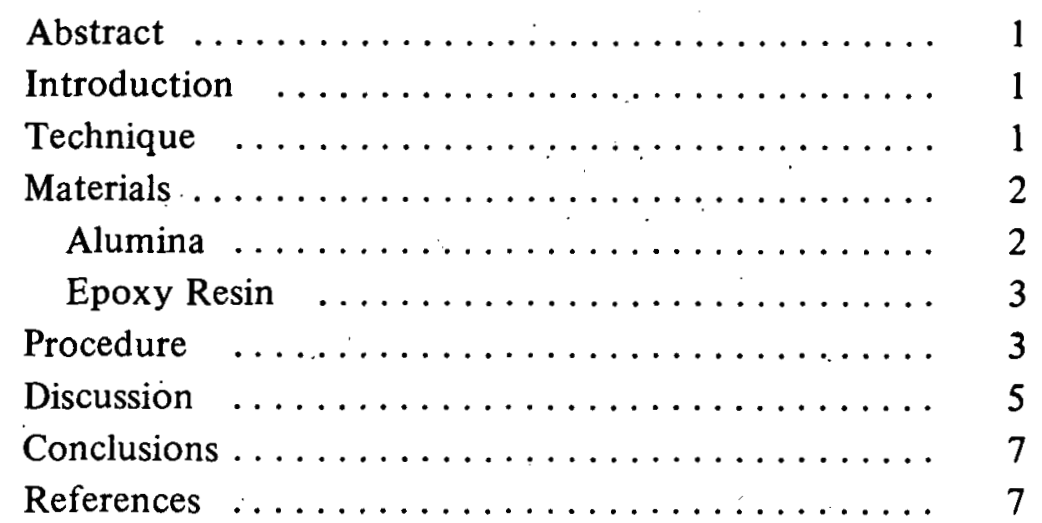


RFP-1813 


\title{
A VACUUM POTTING TECHNIQUE FOR METALLOGRAPHIC SPECIMENS USING BLACK EPOXY RESIN AND BLACK ALUMINA FILLER
}

\author{
Arthur E. Calabra and Delmar V. Miley
}

\begin{abstract}
The technique of vacuum mounting a metallographic specimen in a mixture of black pelletized alumina and a low-temperature curing black epoxy resin provides the Metallography Laboratory with a very versatile and efficient mounting medium. The resulting product has all the characteristics of a potting material of extremely high quality. These desirable characteristics include minimal mold shrinkage, minimal reflectivity from the mount surface for superior photomicrography, and abrasion resistance which results in excellent specimen edge retention.
\end{abstract}

\section{INTRODUCTION}

The demands made on the metallographer are ever increasing in our technologically oriented society. No longer is the metallographer's work devoted entirely to the evaluation of large samples where the interest lies only in the bulk of the material. From the fabrication streams and the reseaılı dind devclopment divisions of industry, we are now asked to metallographically evaluate delicate and intricately fabricated parts, sometimes made of more than one material, and often having small weldments. Therefore, the selection of a mounting material which facilitates handling and preparation is the metallographer's first concern. This mounting medium will determine the efficiency and success in resolving the edge-to-edge structural characteristics of the sample.

There are seven basic requirements for a metallographic-specimen mounting material to be of high quality. These requirements are:

1. Approximately the same abrasive resistance as the specimen to ensure edge retention.

2. Minimal mold shrinkage during and after curing.

\section{Inertness to reagents.}

4. Ability to harden without high temperature and/or high pressure.

5. Minimal curing stresses.

6. Adaptability to specimen shape without distorting on damaging the sample.

7. Minimal reflectivity for photomicrography.

There is no single potting material that can meet all of the above requirements. However, the combination of materials and the technique described in this report does result in a specimen mount which will meet these requirements. The method is versatile, efficient, and effective. Specimens which would be difficult or impossible to prepare by other metallographic techniques are successfully and routinely prepared by this procedure.

\section{TERHNIQIF.}

The metallographic mounting technique to be described consists of vacuum potting in a mixture of black pelletized alumina marketed as Metallogrip $\mathrm{D}^{(9)}$, and a low-temperature curing black epoxy resin known as Maraset. ${ }^{(2,3)}$ The materials and methods are described in detail.

Figure 1 shows the excellent metallographic results which can be obtained. The specimen is a section from a friable sheet of electron-beam evaporated beryllium. The black alumina and black epoxy resin minimized the surface reflection for unaffected photomicrography. The alumina filler maintained the specimen edges. The ability of the mixture to cure at a low temperature and without pressure, cure with minimal shrinkage, and cure with negligible curing stresses enabled this fragile sheet to be mounted without damage and metallographically prepared. 


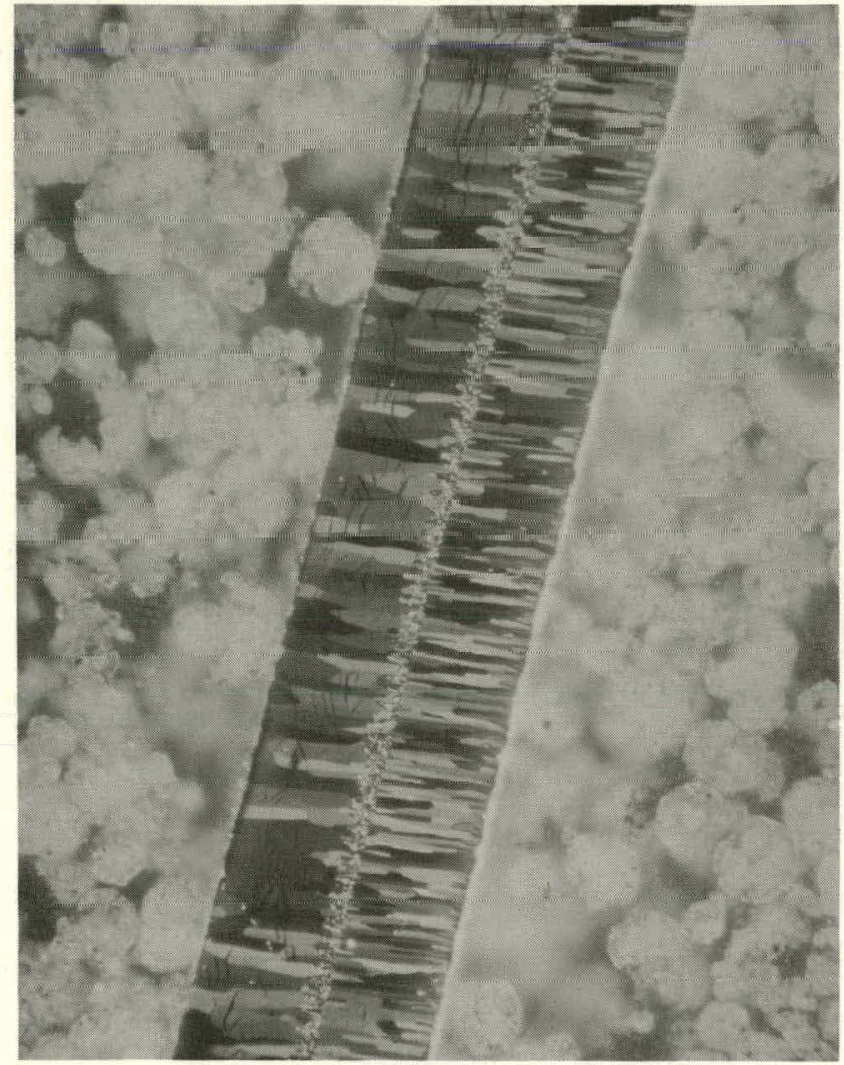

Figure 1. Electron-beam evaporated beryllium sheet $(0.005-$ in. thick, $\mathrm{R}_{\mathrm{B}}=80$ ) mounted in a mixture of black Metallogrip $D$ of medium hard grade (-150 mesh) and black Maraset, by the vacuum mounting technique. The structural characteristics are clearly defined. 200X Polarized illumination.

\section{MATERIALS}

ALUMINA - Metallogrip $\mathrm{D}^{(1)}$ is a black pelletized alumina which is available in two mesh sizes, -150 and +150 mesh (Standard Tyler). The fine mesh is normally used for the complexshaped samples and those that have convolutes, holes, and threads to be penetrated. The +150 mesh is recommended for the more regular-shaped specimens.

There are three hardness grades - soft, medium, and hard, in each mesh size. The grades are matched with the hardness of the material to be metallographically prepared. See Table I as a general guide for matching hardness grade to material.

Each alumina body is cup-shaped and has a rough inner and outer surface. The epoxy resin, by vacuum outgassing, will penetrate each body, giving an intimate bond which will prevent the
TABLE I Guide for Matrhing Metallogrip D Hardness Grade to Metallographic Specimen Material

\begin{tabular}{|c|c|c|}
\hline HARDNF.SS & & MATERIAI \\
\hline GRADE & MATERIAL & HARDNESS \\
\hline Soft & $\begin{array}{l}\text { Suft, nonferrous materials; } \\
\text { e.g., } \mathrm{Ag}, \mathrm{Al}, \mathrm{Cu}, \mathrm{Pb} \text {, etc. }\end{array}$ & $\begin{array}{l}\text { Kockwell B } \\
\quad<50\end{array}$ \\
\hline Medium & $\begin{array}{l}\text { Soft steels, most cast irons, } \\
\text { some nonferrous metals and } \\
\text { alloys; e.g., Be, Monel } \\
\text { brass, bronze, etc. }\end{array}$ & $\begin{array}{l}\text { Rockwell B } \\
>50<100\end{array}$ \\
\hline IIard & $\begin{array}{l}\text { Ilardened steels, liard metals } \\
\text { and alloyrs. }\end{array}$ & $\begin{array}{l}\text { Rockwell C } \\
>20\end{array}$ \\
\hline
\end{tabular}

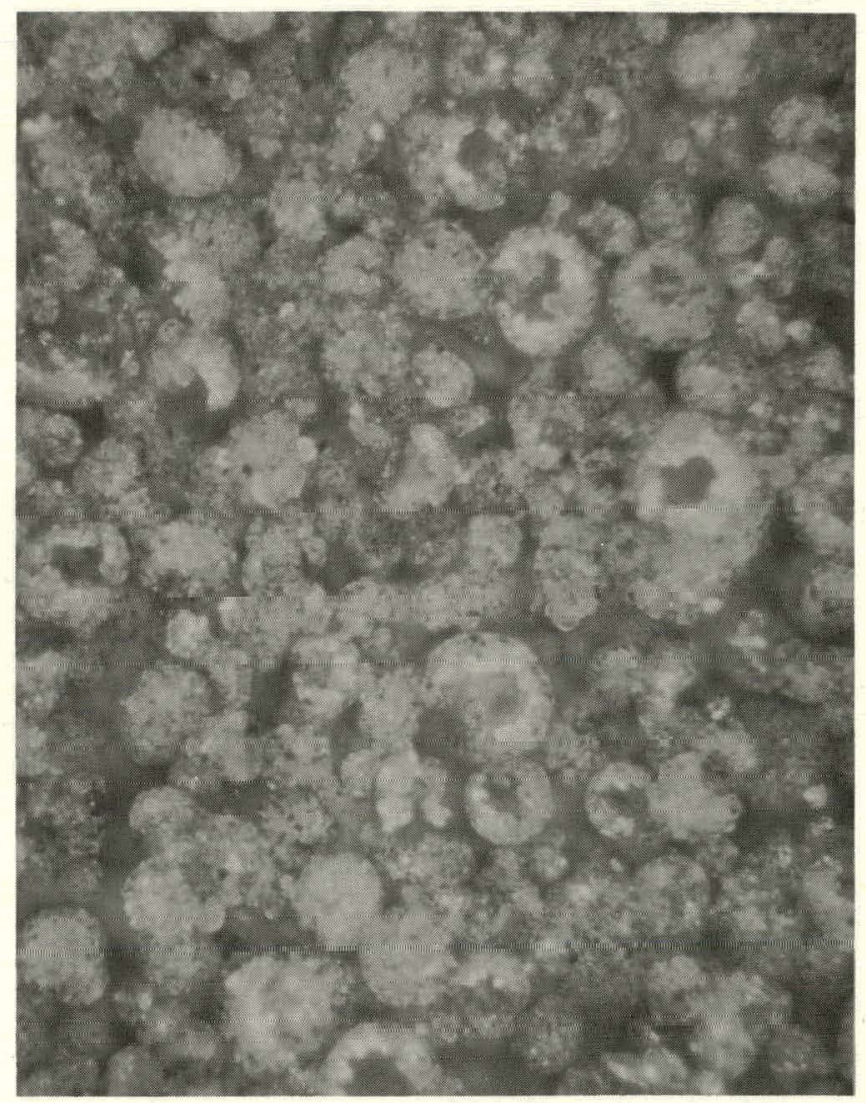

Figure 2. Metallogrip D black alumina mounting filler bodies (-150 mesh) in black Maraset. Note the "cup-shape" of the bodies. Also the stacking of the bodies is very dense, leaving only a minor surface area without an alumina body exposed. Objectionable surface reflection is negligible. 200X Polarized illumination.

particle from being pulled out and scratching the sample during the grinding and polishing operation. See Figure 2. 
EPOXY RESIN - Maraset ${ }^{(2)}$ is a two-part thermosetting epoxy resin possessing the most desirable properties for this vacuum mounting technique. The resin and hardner may be mixed together in convenient batches and stored under refrigeration for several weeks. The epoxy resin will cure at approximately $65^{\circ}$ Celsius in about 12 hours. However, before it cures, it will remain very fluid at $65^{\circ} \mathrm{C}$ for over one hour. This feature is most desirable; it allows complete vacuum impregnation of the alumina bodies and, under vacuum, allows the alumina-epoxy mixture to penetrate into the sample contours. Also, prior lo curing and during the highly fluid period the filler material will settle and stack around the sample, forming a dense, abrasion-resistant layer. Some of the faster-curing resins also conform well to specimen contours, but they do not remain sufficiently fluid for a long enough time to allow complete settling of the filler material.

Maraset is normally a clear resin, but for this technique, a black dye is added to achieve a less-reflective material. The dye is also available from the Marblett Corp., and comes in either a paste or powder form. ${ }^{(3)}$

Another desirable property of Maraset is relatively low shrinkage during curing. The addition of the filler material further reduces the shrinkage effect by providing countless little surfaces to effectively "absorb" the shrinkage, resulting in almost no shrinkage gap between the sample and the mounting material. By eliminating this annoying shrinkage gap, sample edge retention is improved, cross-contamination by entrapped grit particles is avoided, and staining caused by seepage of lubricants and etchants is minimized.

Curing stresses associated with some epoxy resins can be great enough to cause damage in very fragile specimens. ${ }^{(4)}$ The low curing temperature of Maraset $\left(65^{\circ} \mathrm{C}\right)$ gives this resin inherently low internal stresses during curing. The filler material also helps to evenly distribute the curing stresses, thereby further minimizing the possibility of damaging a delicate specimen.

The Maraset epoxy resin is inert to standard lubricants, and polishing and etching solutions. However, it will soften after prolonged contact with acetone, carbon tetrachloride, or alcohol. If a sample must be removed from the mount, a solvent such as Plastisolve ${ }^{(5)}$ will dissolve the resin without damage to the sample.

\section{PROCEDURE}

The specimen is placed in a reusable silicone rubber mold. These molds are available from Buehler Ltd. ${ }^{(6)}$ and Scandinavian Diamond Products $^{(7)}$ in 1-, 1.25- and 1.50-in. diameters (see Figure 3). Delicate or small specimens can be supported in these molds by paper clips, wires, small alligator clamps, or staples. With experience and imagination the technician will become quite versatile in his sample supporting technique.

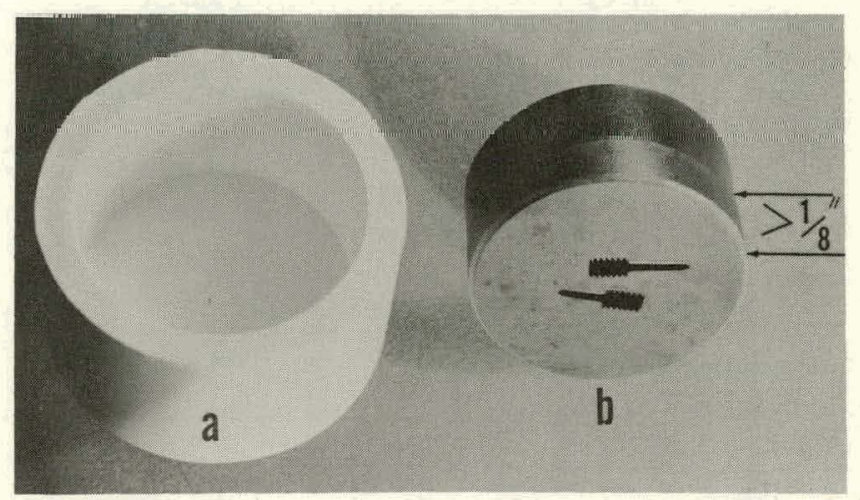

Figure 3. Reusable silicone rubber mold (a), and cured mount of the Maraset-Metallogrip D mixture (b).

The alumina hardness and mesh size is then selected to match the sample hardness and configuration (see Figures 4 and 5). The amount of filler material to be added will depend upon the amount of material that must be removed from the specimen to reveal the desired plane of examination. The mount should have at least $1 / 8$ in. of packed alumina filler remaining after grinding and polishing (see Figure 3 ).

The required amount of Maraset and Metallogrip $\mathrm{D}$ can be mixed in a paper cup. Each 1.25-in. mold will hold approximately $20 \mathrm{cc}$ of epoxy-alumina mixture. The mixture is placed in a vacuum oven preheated to $65^{\circ} \mathrm{C}$ (Figure 6) and outgassed to ensure complete wetting of each alumina body by the epoxy. The mixture is removed from the vacuum oven after the heavy froth has subsided, and then it is allowed to stand for a few minutes. The alumina will settle out, leaving a layer of essentially alumina-free epoxy, and a layer of epoxy with a high concentration of alumina. The epoxy layer is decanted into a second cup, and the remaining alumina-epoxy mixture is distributed to each mold. Enough epoxy from the second cup is then added to fill each mold approximately half full. 


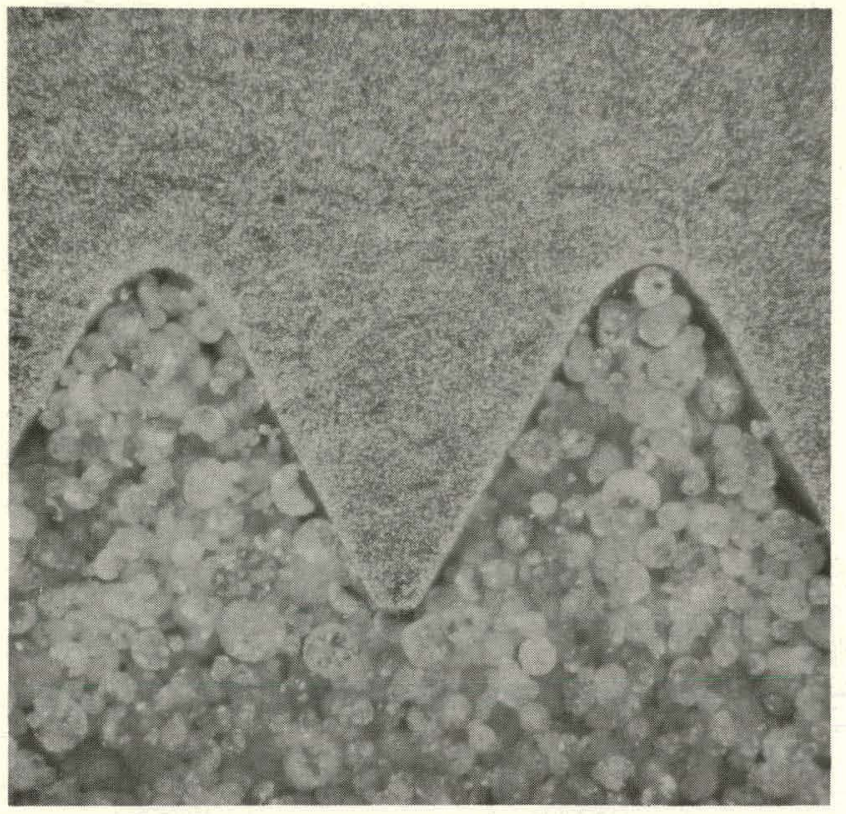

Figure 4. The vacuum mounting technique has enabled the alumina filler to penetrate to the root of the threads of a uranium alloy $\left(R_{C}=40\right)$ screw. Metallogrip $D$, hard grade of -150 mesh was used as the filler. 75X Polarized illumination.

The molds are then placed in the vacuum oven and outgassed to ensure complete contact of the alumina-epoxy mixture with all specimen surfaces. Normally 4 or 5 minutes of outgassing will suffice. Outgassing should be watched and the vacuum controlled to prevent the mixture from bubbling over the top of the mold. After this outgassing is complete, the molds are filled with epoxy from the second cup and placed in the oven to cure. It is advisable not to cure under vacuum so that the alumina particles can settle and efficiently stack.

Approximately 12 hours is required to fully cure the mounts. It is therefore advisable to prepare the mounts near the end of the shift and allow them to cure overnight. They will then be ready for metallographic preparation the following morning.

Grinding and polishing of the mounted sample does require additional preparation time. The abrasion resistance of the mount is now similar to that of the specimen, therefore the entire mount surface, in effect, is being ground and polished. Grinding papers should be changed frequently to minimize the introduction of an abnormal depth of flowed metal on the specimen. ${ }^{(8)}$ Also, excessive ultrasonic cleaning should be avoided. ${ }^{(9)}$

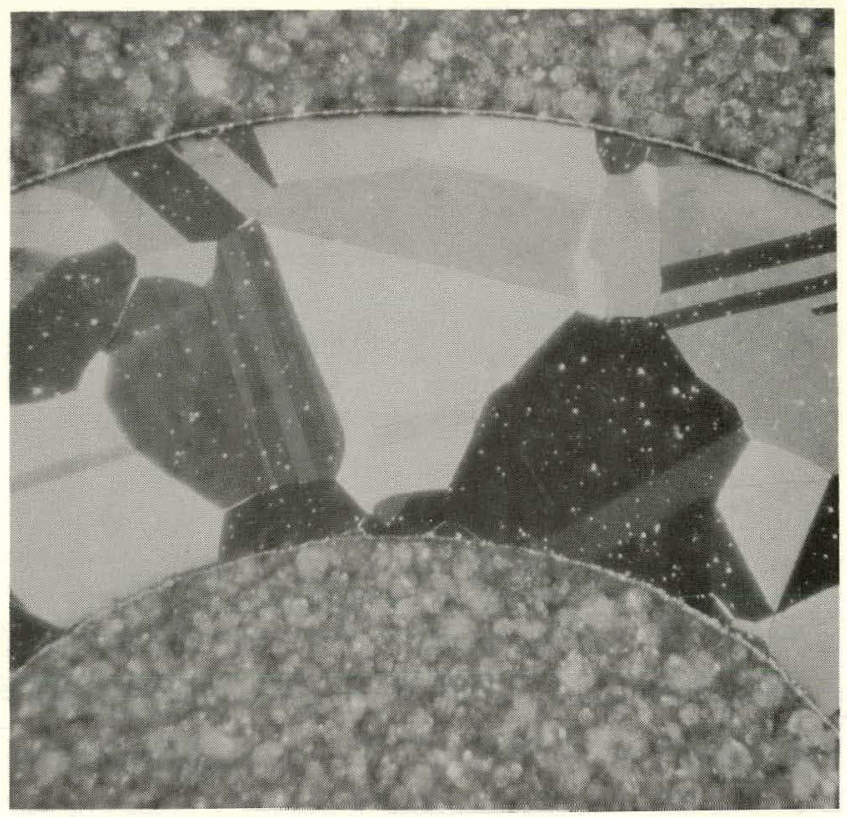

Figure 5. Transverse section of a Monel tube prepared using the described mounting technique. Alloy 400 Monel tubing, 0.092-in. o.d. by 0.050 -in. i.d., $R_{B}=75$ (approx.), -150 mesh, medium hard Metallogrip D. The center of the tube is completely filled allowing excellent edge-to-edge retention. The grain structure is sharp and is not washed out by scattered light from a highly reflective mount surface. $75 \mathrm{X}$ Polarized illumination.

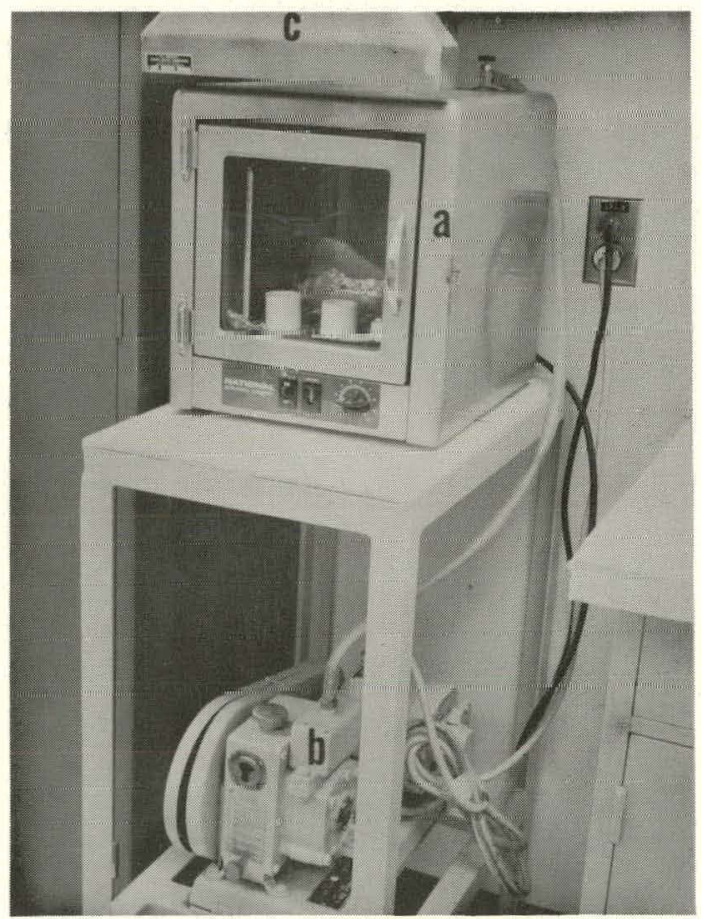

Figure 6. Vacuum oven (a) connected to a small mechanical vacuum pump (b). Temperature is maintained at $65^{\circ} \mathrm{C}$. Inside of oven measures 8 by 8 by 12 inches. A hood (c) draws off the small amount of vapors that are present when the oven door is opened. 


\section{DISCUSSION}

The metallographic mounting technique described in this report is somewhat more time consuming than other techniques, both for the preparation of the mount and for the subsequent grinding and polishing operations. However, the extra effort required is justified by the high quality metallography that can be obtained. It should also be pointed out that this (or any other) metallographic technique is not "fool proof". Care must always be taken to follow good, standard metallographic practice in regard to sample handling, cleanliness, abrasive selection, and lubrication.

The advantages of the vacuum potting technique using black alumina and epoxy can be demonstrated with several comparative photomicrographs. Figures 1 and 7 show sections of a sheet of electron beam evaporated beryllium approximately 0.005 -in. thick. The sample in Figure 1 was mounted using the technique

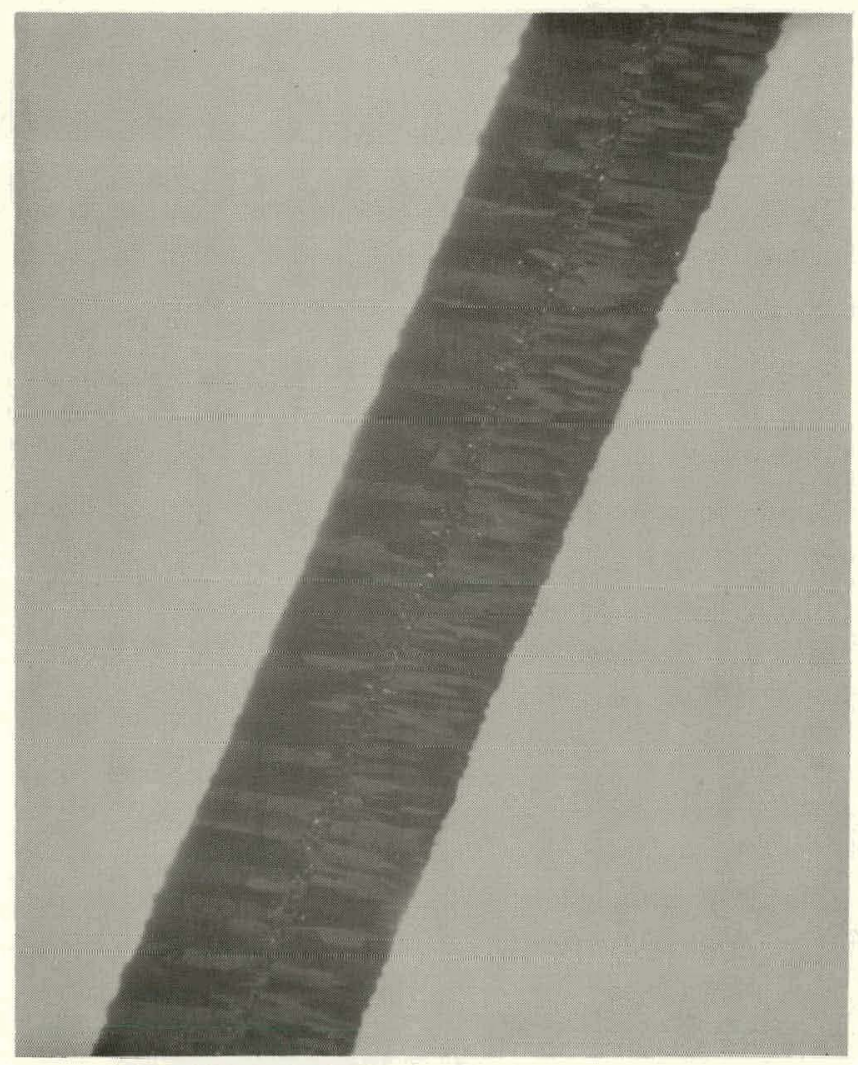

Figure 7. The same beryllium sheet as shown in Figure 1, but mounted by a method described in References 10 and 11. The highly reflective mount surface has "washed-out" the structural characteristics of the sample. 200X Polarized illumination. described in this report, and the sample in Figure 7 was mounted by a similar, but less effective technique previously reported. ${ }^{(10,11)}$ In Figure 1 , the beryllium structure is revealed in sharp, clear detail, and the specimen edges are keen and distinct.

By contrast, the structure shown in Figure 7 appears "washed out" because of the high reflectivity of the mount material. It appears that edge retention is satisfactory on this specimen, but because of the high reflection, edge detail is not clearly revealed.

A similar pair of specimens is shown in Figure 8a and $8 \mathrm{~b}$. These are from another, thinner sheet of electron beam evaporated beryllium, but in this case there is also a 0.0003 -in. reaction layer of the beryllium and copper substrate. The previous comparisons are again evident, but note also that in Figure 8a the substrate is distinctly revealed, and in Figure $8 \mathrm{~b}$ the substrate is completely lost.

Figures $9 \mathrm{a}$ and $9 \mathrm{~b}$ show the ability of the black alumina-epoxy mounting media to conform to an irregular specimen shape, and to retain the edge for critical examination. These two samples are the fractured ends of beryllium tensile specimens. In Figure 9a, note how the alumina particles are in intimate contact with the irregular fracture surface, and how the sample edge is retained. Also, the negligible light reflection from the black mount surface resulted in a high quality photomicrograph.

The sample shown in Figure 9b was mounted with white alumina and clear epoxy. $(10,11)$ The sample edge is retained, but because of the very high reflectivity of the mount, observation of the edge is obscured. Even though this sample is well prepared, much of the contrast between grains is lost because of scattered light from the mount material.

Another example of edge retention on an irregularly shaped specimen is presented in Figure 10. This photomicrograph shows the fractured end of a stainless steel micro tensile specimen. 

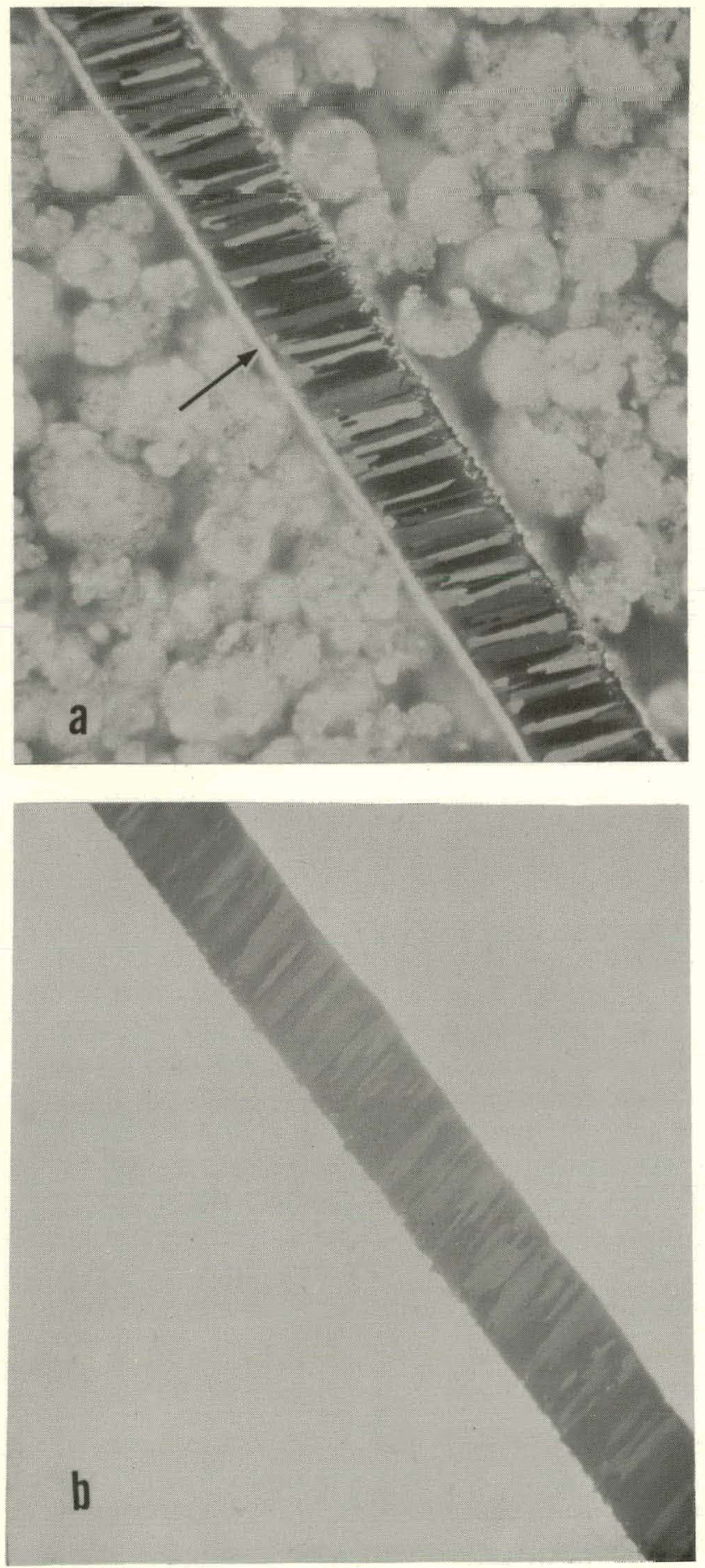

Figure 8 . Electron-beam evaporated beryllium sheet $(0.003-$ in. thick $-R_{B}=80$ having a 0.0003 -in. reaction layer of the beryllium and copper substrate). Figure 8a was mounted by the described technique using +150 mesh, medium hard Metallogrip D. Note complete edge retention and the excellent resolution of the beryllium structure. The structure of the substrate $(\rightarrow)$ is not resolved by the polarized illumination; however, it is observable and can be measured. Figure $8 \mathrm{~b}$ is a photomicrograph of the same beryllium sheet mounted in a reflective mount material as described in References 10 and 11. 200X Polarized illumination.
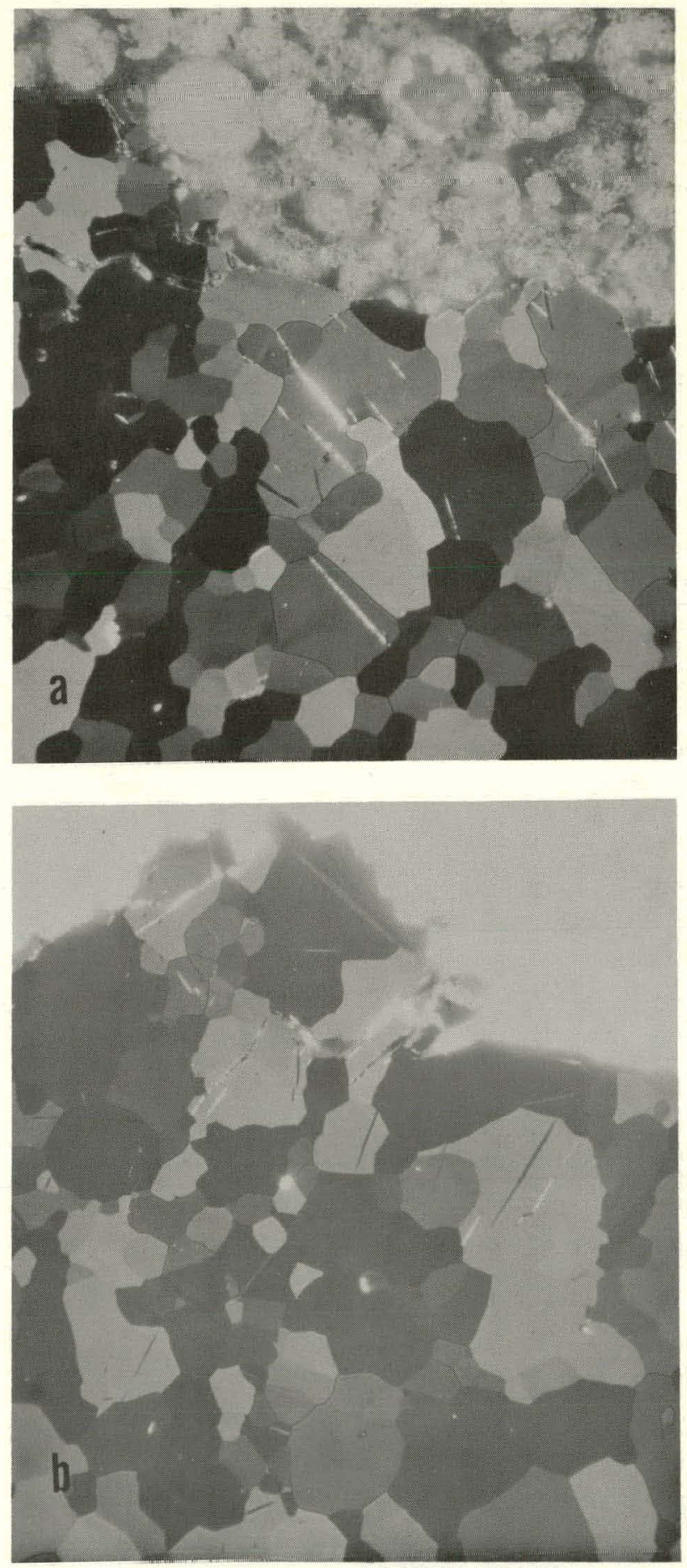

Figure 9. Fractured ends of beryllium tensile specimens mounted by the Maraset-Metallogrip D technique, shown in $9 \mathrm{a}$, and mounted by a previous technique ${ }^{10,11}$, shown in $9 \mathrm{~b}$. The filler material in $9 \mathrm{a}$ is -150 mesh, medium hard Mctallogrip D. Edge retention is excellent, and the structure is well defined. In $9 \mathrm{~b}$, edge retention is satisfactory, but scattered light from the highly reflective mount material obscures the edge and "washes-out" the grain structure. $200 X$ Polarized illumination. 


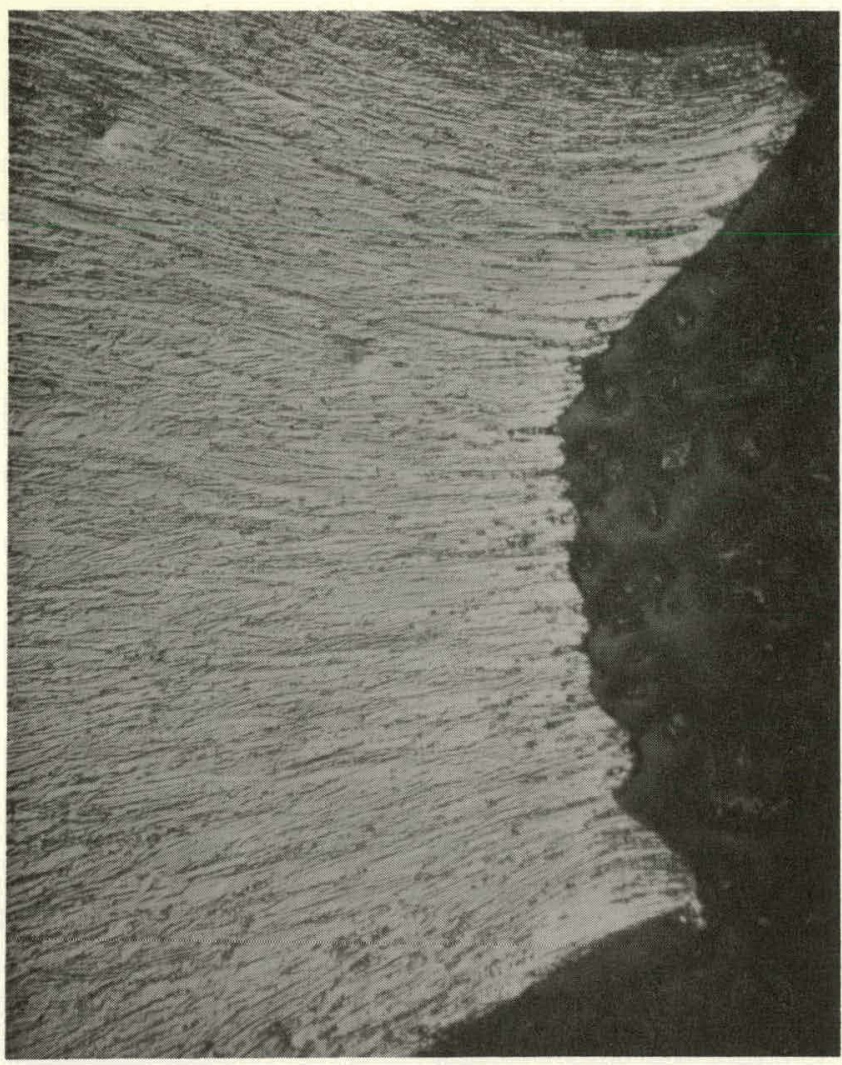

Figure 10. Edge of a ruptured microtensile bar of type $21 \mathrm{C}_{\mathrm{r}}-6 \mathrm{Ni}-9 \mathrm{Mn}$ stainless steel. 200X Differential Interference Contrast.

\section{CONCLUSIONS}

A mixture of black Maraset and Metallogrip D, used in a vacuum mounting technique, fulfills all the criteria of a metallographic mounting medium of very high quality.

The nonreflective surface of the mount material results in photomicrographs of high quality, especially when using polarized illumination.

This technique allows the mount material to be customized to the specimen.

Specimens that were impossible or extremely difficult to mount are now routinely metallographically prepared.

\section{REFERENCES}

1. Metallogrip D, AMCERMET - American Ceramic and Metallurgical Corp., P.O. Box 667, Hendersonville, North Carolina 28739.

2. Maraset Epoxy Resin, Maraglas Type A (655 Resin/555 Hardener), The Marblette Company, c/o Allied Product Corp., 37-31 30th Street, Long Island City, New York 11102.

3. Black paste or black powder die for Maraglas Type A, The Marblette Company, c/o Allied Product Corp., 37-31 30th Street, Long Island City, New York 11102.

4. R. C. Crouse and R. J. Gray, An Effect of Curing Stresses in Epoxy Resins, Oak Ridge National Laboratory, Oak Ridge, Tennessee, published in Advances in Metallography, USAEC RFP 658, edited by R. J. Jackson and A. E. Calabra, Rocky Flats Division, Dow Chemical U.S.A., Golden, Colorado 80401.

5. Plastisolve, Ladd Research Industries, Inc., P.O. Box 901, Burlington, Vermont 05401.

6. Met-Grip, Buehler Ltd. 2120 Greenwood Street, Evanston, Illinois 60204.

7. Scandiform, Scandinavian Diamond Products, Denmark, local supplier - T.C. Jarrett Co., P.O. Box 05397, Denver, Colorado 80215.

8. A. E. Calabra and R. J. Jackson, Metallographic Techniques For Vacuum-Cast Rolled Ingot Beryllium Sheet, USAEC RFP 962, Rocky Flats Division, Dow Chemical U.S.A., Golden, Colorado 80401.

9. A. E. Calabra, $A$ Rapid and Reliable Metallographic Technique For Silver, USAEC RFP 1823, Rocky Flats Division, Dow Chemical U.S.A., Golden, Colorado 80401.

10. A. E. Calabra, Mounting Metallographic Specimens For Edge Retention, Metals Progress, Vol. 90, No. 1, July 1966, American Society for Metals, Metals Park, Ohio.

11. A. E. Calabra, Mounting Materials and Alumina For Edge Retention in Preparing Metallographic Specimens, USAEC RFP 1104, Rocky Flats Division, Dow Chemical U.S.A., Golden, Colorado 80401, April 2, 1968. 